\title{
A Novel Technique Using Mesh to Repair a Recurrent Large Indirect Inguinoscrotal Hernia
}

\author{
Ho L Chong $\odot^{1}$, Adnan Taib $\odot^{2}$, Andrew N Wilson $\odot^{3}$, Muhammad A Khan ${ }^{4}$, Alexandrina Braniste $\odot^{5}$, Ateeq Jamil ${ }^{6}$, Ali Warsi ${ }^{7}$
}

\begin{abstract}
Background: The positioning of a slit mesh around cord structures during laparoscopic transabdominal preperitoneal (TAPP) hernia repair rests the mesh better without kinks, thereby minimizing recurrences. However, studies also suggest that insufficient closure of the mesh slit may lead to recurrences.

Aim: This report describes a novel technique using AbsorbaTacks (Covidien) to close the mesh slit and refashion an artificial 'deep ring' to minimize recurrence.

Technique: We report the case of a fit 82 -year-old Caucasian male presenting with a recurrent large right indirect inguinoscrotal hernia $(8 \mathrm{x}$ $8 \times 7 \mathrm{~cm}$ with $4 \times 4 \mathrm{~cm}$ deep inguinal ring). The patient underwent a TAPP repair with a background of unsuccessful open repair by another surgeon previously. Following mesh deployment, the mesh was lifted up by the cord structures, which was under tension due to a large defect. A slit was made in the inferomedial aspect of the mesh. This allowed it to be wrapped around the cord structures. The overlapped trouser flaps were then stapled together encircling the cord, by AbsorbaTacks to create a secure artificial 'deep ring'. Edges of the mesh were also standardly affixed by AbsorbaTacks to the pectineal ligament and posterior abdominal wall. This creates a secure four-point fixation of the mesh scaffold to prevent 'windsock' effect, which happens when the mesh is pushed into the widened deep inguinal ring, leading to early recurrences. The peritoneal incision was also closed with AbsorbaTacks.

Conclusion: No complications were registered during the early postoperative period. The patient had an uneventful recovery and was discharged within 20 hours with simple analgesia. No recurrence was reported during the 6 months follow-up period.

Clinical significance: The anchoring of a slit mesh with tackers around the cord structures can be used to repair large recurrent inguinal hernias laparoscopically following an open repair. This technique potentially minimizes further recurrences.

Keywords: Case report, Inguinoscrotal hernia, Laparoscopy, Mesh fixation, Mesh migration, Recurrent, Slit mesh, Transabdominal preperitoneal (TAPP).

Abbreviations: TAPP: Transabdominal preperitoneal; TEP: Totally extraperitoneal

World Journal of Laparoscopic Surgery (2021): 10.5005/jp-journals-10033-1429
\end{abstract}

\section{BACKGROUND}

Inguinal hernia repairs are one of the most commonly performed general surgical procedures worldwide.' Annually, more than 75,000 hernia repairs with mesh are performed within the National Health Service in England alone. ${ }^{2}$ Primary and recurrent inguinal hernia repairs can be carried out openly or laparoscopically. A laparoscopic mesh repair, an evolving technique, is well known for its minimally invasive advantages, such as less postoperative pain, earlier recovery, and shorter hospital stay, as compared to an open repair. ${ }^{3}$ Depending on the approach, a laparoscopic transabdominal preperitoneal (TAPP) hernia repair or totally extraperitoneal (TEP) hernia repair can be performed. ${ }^{4}$

Available evidence suggests that a considerable proportion (15\%) of all inguinal herniorrhaphies are performed due to recurrences, ${ }^{5}$ which may be due to structural weakness of the abdominal wall and distorted anatomy. ${ }^{6}$ The European Hernia Society guidelines have recommended that a posterior preperitoneal approach should be the procedure of choice for the management of all recurrent inguinal hernias after previous open repair unless otherwise indicated. ${ }^{7}$

However, there is controversy arising around the optimal technique for mesh placement within the preperitoneal space during a TAPP repair. ${ }^{8}$ Some surgeons presume that the positioning of a slit mesh around the cord structures rests the mesh better without kinks, thereby minimizing recurrences.
${ }^{1-7}$ Department of General Surgery, University Hospitals of Morecambe Bay NHS Foundation Trust, Furness General Hospital, Cumbria, England, United Kingdom

Corresponding Author: Ho L Chong, Department of General Surgery, University Hospitals of Morecambe Bay NHS Foundation Trust, Furness General Hospital, Cumbria, England, United Kingdom, Phone: +44 7475252656, e-mail: h.l.chong@lancaster.ac.uk

How to cite this article: Chong HL, Taib A, Wilson AN, et al. A Novel Technique Using Mesh to Repair a Recurrent Large Indirect Inguinoscrotal Hernia. World J Lap Surg 2021;14(1):65-67.

Source of support: Nil

Conflict of interest: None

However, studies also suggest that insufficient closure of the mesh slit may lead to further recurrences. ${ }^{12}$ This report describes a novel technique using AbsorbaTacks (Covidien) to close the mesh slit and refashion a deep artificial ring in a large recurrent inguinoscrotal hernia to achieve a successful repair.

\section{Technique}

We report the case of a fit 82-year-old Caucasian male, presenting with a recurrent large right indirect inguinoscrotal hernia $(8 \times 8 \times 7 \mathrm{~cm}$ with $4 \times 4 \mathrm{~cm}$ deep ring). This patient underwent a 




Fig. 1: Laparoscopic view of the large right indirect inguinoscrotal hernia

TAPP repair (Fig. 1). He had previously undergone an open surgical repair performed by another surgeon.

Under general anaesthesia, the ports and a pneumoperitoneum were established. Using the standard Hasson technique, a 10-mm supraumbilical camera port and two 5 -mm bilateral operating ports $4 \mathrm{~cm}$ equidistant to the umbilicus were inserted under direct vision. The patient was placed in a Trendelenburg position ( $30^{\circ}$ head down).

After inspection of the inguinal region, the peritoneum was transversely opened $2 \mathrm{~cm}$ above the upper border of the direct inguinal ring. Dissection of the preperitoneal space was carried out to identify and expose the key anatomical landmarks in the retroinguinal space. Subsequently, the indirect hernia sac was carefully dissected from the spermatic cord and was reduced.

A polyester mesh of size $10 \times 15 \mathrm{~cm}$ (Prietex 2D heavyweight) was fashioned to the appropriate size and deployed into the preperitoneal space. An effort was made to ensure that the mesh was positioned flatly over the cord structures without any kinks. However, the inferomedial aspect of the mesh seemed to be lifted up due to the tight cord structures, which were stretched over a large direct inguinal ring.

As the femoral vessels lie at very close proximity to the inferomedial corner of mesh there were no natural structures to fix the mesh onto safely. Therefore, a slit was made to the inferomedial aspect of the mesh directly over and posterior to the cord. To encircle the cord within the slit, the two legs of the trouser flaps were carefully anchored together anterior to the cord using two AbsorbaTacks. This created an artificial deep ring to hold the mesh firmly around the cord structures (Fig. 2).

AbsorbaTacks were used to fix the inferomedial edge of the mesh to pectineal ligament and onto the posterior abdominal wall (superomedially, and also laterally). Two additional tackers were also used to secure the mesh firmly along the superior border. Together with the inferior medial AbsorbaTacks forming an artificial deep ring, the mesh scaffold was held more securely by a '4-point fixation' instead of the standard '3-point fixation' (Fig. 3).

The peritoneal incision was closed with AbsorbaTacks. Trocars were removed under direct vision. The $10 \mathrm{~mm}$ supraumbilical port was closed with size 1-J Vicryl and the skin was closed with staples. $20 \mathrm{~mL}$ of $0.25 \%$ Marcaine was infiltrated to the ports for analgesia and $10 \mathrm{~mL}$ was infiltrated for a right ilioinguinal nerve block.

\section{Results}

The patient had an uneventful recovery and was discharged within 20 hours of the operation with simple analgesia. No

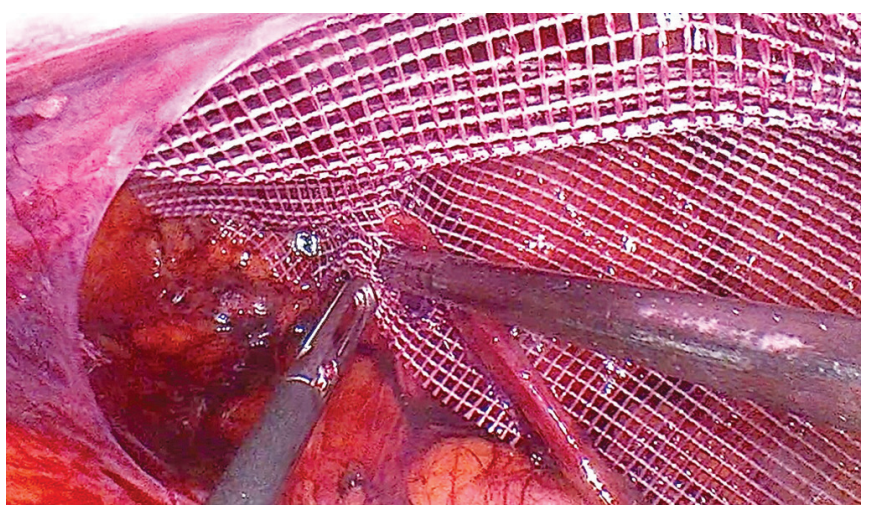

Fig. 2: Laparoscopic view of the trouser flaps anchored and overlapped by AbsorbaTacks

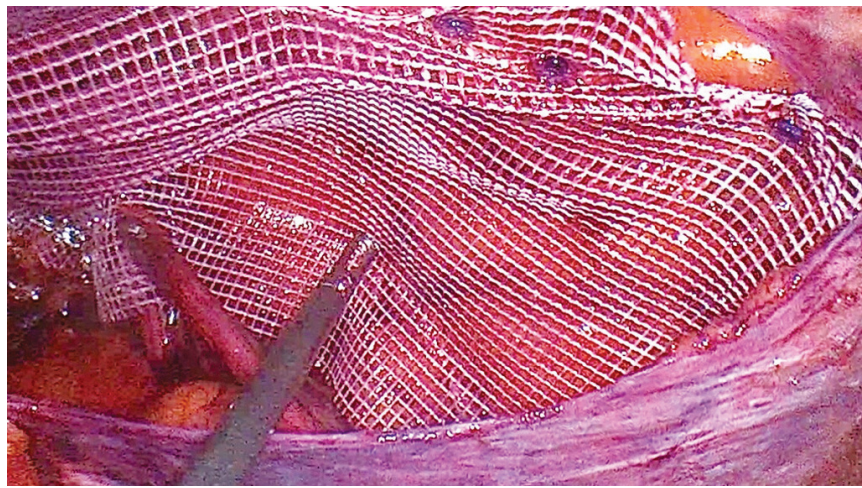

Fig. 3: Laparoscopic view of mesh fixation

recurrence at 6 months nor any complaint of chronic pain were reported.

\section{Discussion}

A tension-free repair of large recurrent inguinal hernias is often technically challenging due to intrinsically weakened muscles of the abdominal wall, scar tissue formation, as well as distorted anatomy. ${ }^{6}$ In a randomized trial of 1983 patients, Neumayer et al. concluded that the recurrence rate of a laparoscopic repair was up to $10.1 \% .{ }^{9}$ With mesh techniques, it is established that mesh cannot match the properties of natural tissue, which often leads to displacement. Apart from mesh displacement, Fitzgibbons et al. stated that potential mechanisms of recurrences also include folding or invagination of mesh and migration of mesh, ${ }^{10}$ which is akin to a 'windsock effect'.

In normal anatomy, the deep inguinal ring transmits the spermatic cord in the male and the round ligament of the uterus in the female into the inguinal canal. Due to the inconsistency of tension within the weakened abdominal wall, cord structures may exert mechanical stress along the inferior edge of the mesh, which will alter mesh position over time. ${ }^{3}$ By introducing a slit, this allows the mesh to 'sit' better without folding as the slit creates a space which allows cord structures to pass through.

Usually, mesh fixation at the inferior aspect is precluded due to the femoral vessels in the 'triangle of doom' medially and the 'triangle of pain' laterally. ${ }^{13}$ Thus, stapling the trouser flaps to encircle the cord structures help to securely fasten the mesh inferiorly. This helps to prevent folding of mesh within the preperitoneal space 
and to avoid superior leverage of mesh by the cord structures, thus reducing the risk of recurrence.

Currently, evidence for a reduction in recurrence by the slit mesh placement technique is inconclusive. ${ }^{8}$ There are only three studies comparing the outcomes of slit vs non-slit mesh during a laparoscopic TAPP repair. ${ }^{11,12,14}$ Although these studies failed to prove an advantageous difference with slit mesh in terms of recurrence rate, none of them are well designed randomised controlled trials.

Leibl et al. suggested that some recurrences are associated with insufficient closure of the mesh slit. ${ }^{12}$ This may be due to two reasons. First, it has been well documented that mesh shrinkage is a major issue in laparoscopic hernia repair. ${ }^{15}$ It is generally recognized that intraperitoneally placed mesh will shrink up to $40 \%$ and lose its flexibility considerably, after five years. ${ }^{16}$ Second, gas insufflation of the abdominal cavity is a crucial element in laparoscopic surgery which significantly expands the abdominal surface volume. The effects of abdominal deflation after surgery and the anticipated mesh shrinkage over time may therefore result in dislodgment of the cord structure from the slit. Therefore, by anchoring the two trouser flaps of the mesh slit together around the cord structures, a secure fixation point is created. This fixation point anchors the mesh in a consistent location, which helps to ensure coverage of the myopectineal orifice despite the effects of mesh shrinkage. ${ }^{17}$ Moreover, this also refashions a deep artificial ring to prevent re-entry of intra-abdominal content through the defective deep inguinal ring. Regarding concerns of circumferential scaring causing postoperative pain, there is no evidence of spermatic cord injury caused by slit mesh reported. ${ }^{18}$

Finally, fixation of mesh edges onto the abdominal wall distributes tension across the mesh surface, hence smoothing out the folds. The secured positioning prevents 'windsock' effect, where the mesh becomes distally displaced as it may travel along the cord if it were only fixed onto it.

\section{Conclusion}

We conclude that the creation of a new deep ring around the cord structures using a slit mesh and tacks is a novel and successful technique that could be used to repair large recurrent inguinal hernias laparoscopically to minimize further recurrence.

\section{Declarations}

Ethics approval and consent to participate: This research does not require Ethics Committee approval. All the procedures have been performed in accordance with the Helsinki Declaration of 1964 and later versions.

Consent for publication: Written informed consent was obtained from the patient regarding the publication of this paper and the associated images.

Availability of data and material: Not applicable.

\section{OrCID}

Ho L Chong: @ https://orcid.org/0000-0001-8313-1791

Andrew N Wilson: (1) https://orcid.org/0000-0003-0269-159X

Alexandrina Braniste: (1) https://orcid.org/0000-0003-2182-4570

Adnan Taib: @ https://orcid.org/0000-0002-8115-1585

\section{References}

1. Belyansky I, Tsirline VB, Klima DA, et al. Prospective, comparative study of postoperative quality of life in TEP, TAPP, and modified Lichtenstein repairs. Ann Surg 2011;254(5):709-715. DOI: 10.1097/ SLA.0b013e3182359d07.

2. Pawlak M, Tulloh B, de Beaux A. Current trends in hernia surgery in NHS England. AnnR Coll Surg Engl 2020;102(1):25-27. DOI: 10.1308/ rcsann.2019.0118.

3. Saber A, Hokkam EN, Ellabban GM. Laparoscopic transabdominal preperitoneal approach for recurrent inguinal hernia: A randomized trial. J Minim Access Surg 2015;11(2):123-128. DOI: 10.4103/09729941.153809.

4. Bracale U, Melillo P, Pignata G, et al. Which is the best laparoscopic approach for inguinal hernia repair: TEP or TAPP? A systematic review of the literature with a network meta-analysis. Surg Endosc 2012;26(12):3355-3366. DOI: 10.1007/s00464-012-2382-5.

5. Saber A, Ellabban GM, Gad MA, et al. Open preperitoneal versus anterior approach for recurrent inguinal hernia: a randomized study. BMC Surg 2012;12(1):22. DOI: 10.1186/1471-2482-12-22.

6. Campanelli G, Pettinari D, Nicolosi FM, et al. Inguinal hernia recurrence: classification and approach. Hernia 2006;10(2):159-161. DOI: 10.1007/s10029-005-0053-3.

7. Simons MP, Aufenacker T, Bay-Nielsen M, et al. European Hernia Society guidelines on the treatment of inguinal hernia in adult patients. Hernia 2009;13(4):343-403. DOI: 10.1007/s10029-0090529-7.

8. Bracale U, Andreuccetti J, Sodo M, et al. Lack of advantages of slit mesh placement during laparoscopic transabdominal preperitoneal inguinal hernia repair (TAPP): a single-center, case-matched study. BMC Surg 2018;18(1):75. DOI: 10.1186/s12893-018-0409-0.

9. Neumayer L, Giobbie-Hurder A, Jonasson O, et al. Open mesh versus laparoscopic mesh repair of inguinal hernia. N Engl J Med 2004;350(18):1819-1827. DOI: 10.1056/NEJMoa040093.

10. Fitzgibbons RJ, Puri V. Laparoscopic inguinal hernia repair. Am Surg 2006;72(3):197-206.

11. Leibl BJ, Kraft B, Redecke JD, et al. Are postoperative complaints and complications influenced by different techniques in fashioning and fixing the mesh in transperitoneal laparoscopic hernioplasty? Results of a prospective randomized trial. World J Surg 2002;26(12):14811484. DOI: 10.1007/s00268-002-6204-0.

12. Leibl BJ, Schmedt CG, Schwarz J, et al. A single institution's experience with transperitoneal laparoscopic hernia repair. Am J Surg 1998;175(6):446-452. DOI: 10.1016/S0002-9610(98)00074-9.

13. Yang XF, Liu JL. Anatomy essentials for laparoscopic inguinal hernia repair. Ann TransI Med 2016;4(19):372. DOI: 10.21037/atm.2016. 09.32.

14. Velasco JM, Gelman C, Vallina VL. Preperitoneal bilateral inguinal herniorrhaphy. Surg Endosc 1996;10(2):122-127. DOI: 10.1007/ BF00188356.

15. Jonas J. The problem of mesh shrinkage in laparoscopic incisional hernia repair. ZentralbIChir 2009;134(3):209-213. DOI: 10.1055/s-00281098779.

16. Brown CN, Finch JG. Which mesh for hernia repair? Ann R Coll Surg Engl 2010;92(4):272-278. DOI: 10.1308/003588410X12664192076 296.

17. Claus C, Furtado M, Malcher F, et al. Ten golden rules for a safe MIS inguinal hernia repair using a new anatomical concept as a guide. Surg Endosc 2020;34(4):1458-1464. DOI: 10.1007/s00464-020-07449-z.

18. Celik AS, Memmi N, Celebi F, et al. Impact of slit and nonslit mesh technique on testicular perfusion and volume in the early and late postoperative period of the totally extraperitoneal preperitoneal technique in patients with inguinal hernia. Am J Surg 2009;198(2):287-291. DOI: 10.1016/j.amjsurg.2008.11.038. 